\title{
STRES PADA IBU BEKERJA
}

\author{
Friyanka H.D. Sitorus \\ Fakultas Psikologi \\ Universitas Prima Indonesia \\ Jalan Sekip Simpang Sikambing, Medan, Sumatera Utara
}

\begin{abstract}
The decision between becoming a housewife or a working mother is important for women. Nowadays, women who are married and have families generally combine their duties as mothers with work activities because work has become a part of women's lives. It is different from the traditional view where women only have a role to bear children (reproduction) and take care of the household, as if they are limited and placed in a passive position where women are only supporters of the husband's career. The study attempts to find out a comprehensive picture of stress in working mothers. Using qualitative approach, this study involves 6 working mothers in the age range of 20-40 years who had children under 13 years. The result of this study revealed that stress in working mothers is generally caused by external factor, which is occupational stress, followed by family condition and other external factors. Coping stress resources such as good health and high energy are internal resources that minimize the impact of stress. Meanwhile, high self-esteem and interpersonal trust and commitment to family are internal resources. The implication of this study is to consider and anticipate the impact of the mother's decision to work considering the number of working mothers in Indonesia, especially Medan is increasing.
\end{abstract}

Keywords : stress, working mother, coping stress

Abstrak--- Keputusan untuk menjadi ibu rumah tangga atau ibu bekerja, menjadi hal penting bagi banyak wanita. Pada zaman modern ini, wanita yang telah menikah dan berkeluarga umumnya mengkombinasikan tugasnya sebagai ibu dengan kegiatan bekerja karena bekerja telah menjadi bagian dari kehidupan wanita. Berbeda dengan pandangan tradisional dimana wanita hanya memiliki peran untuk melahirkan anak (reproduksi) dan mengurus rumah tangga, seolah dibatasi dan ditempatkan dalam posisi pasif dimana wanita hanyalah pendukung karir suami. Penelitian ini bertujuan untuk melihat gambaran stress pada ibu bekerja secara komprehensif. Penelitian ini menggunakan pendekatan kualitatif yang melibatkan 6 orang ibu pekerja pada rentang usia 20-40 tahun yang memiliki anak dibawah 13 tahun. Hasil penelitian ini menunjukkan bahwa stres pada ibu bekerja umumnya disebabkan oleh faktor eksternal yaitu pekerjaan kemudian disusul dengan kondisi keluarga dan faktor 
eksternal lainnya. Faktor penahan stres seperti kesehatan dan energi yang tinggi menjadi sumber internal yang meminimalisir dampak dari stres. Sementara self esteem dan interpersonal trust yang tinggi serta komitmen pada keluarga merupakan faktor penahan stres bersumber internal. Implikasi dari penelitian ialah sebagai bentuk pertimbangan dan antisipasi terhadap dampak dari keputusan ibu untuk bekerja mempertimbangkan jumlah ibu bekerja di Indonesia, khususnya Medan, yang semakin meningkat.

Kata kunci : Stres, ibu bekerja, coping stress

\section{PENDAHULUAN}

Dewasa ini, peran wanita telah bergeser dari peran tradisional menjadi peran modern. Dalam pandangan tradisional, wanita hanya memiliki peran untuk melahirkan anak (reproduksi) dan mengurus rumah tangga. Tidak hanya itu, peran wanita juga seolah dibatasi dan ditempatkan dalam posisi pasif dimana wanita hanyalah pendukung karir suami. Namun, tidak demikian halnya dengan kondisi saat ini. Pada zaman modern ini, wanita yang telah menikah dan berkeluarga umumnya mengkombinasikan tugasnya sebagai ibu dengan kegiatan bekerja karena bekerja telah menjadi bagian dari kehidupan wanita.

Siregar (2007) menyatakan bahwa ibu bekerja adalah ibu yang melakukan suatu kegiatan di luar rumah dengan tujuan untuk mencari nafkah dalam keluarga. Menurut Siregar, ibu yang bekerja tidak terbatas pada ibu yang bekerja di kantor, memiliki gaji yang tetap, dan bekerja dalam periode waktu yang telah ditentukan. Seorang ibu yang menjual sawah, membuka warung, atau menjual pakaian tetaplah seorang ibu yang bekerja. Lebih lanjut, Encyclopedia of Children's Health yang mengungkapkan bahwa ibu bekerja merupakan seorang ibu yang bekerja di luar rumah untuk mendapatkan penghasilan di samping membesarkan dan mengurus anak di rumah (Siregar, 2011).

Secara khusus, faktor-faktor yang mendasari peningkatan partisipasi dari ibu dalam dunia kerja masih terus dipelajari dan diteliti oleh para ahli ekonomi, sosiologi, dan sejarah. Hanya, terdapat beberapa faktor yang seringkali disebutkan. Pertama, peningkatan jumlah ibu yang bekerja sering dihubungkan dengan pencapaian tingkat 
pendidikan yang lebih tinggi (Dubeck \& Borman, 1996). Wanita yang memiliki tingkat pendidikan hingga jenjang perguruan tinggi akan lebih cenderung untuk bekerja daripada wanita yang tidak memiliki tingkat pendidikan hingga jenjang perguruan tinggi. Kedua, yaitu meningkatnya permintaan tenaga kerja wanita pada lapangan pekerjaan yang didominasi oleh wanita. Hal ini kemudian menyebabkan peningkatan partisipasi ibu dalam dunia kerja (Oppenheimer, 1970 dalam Dubeck \& Borman, 1996). Ketiga, wanita sebagai ibu termotivasi untuk bekerja karena alasan kebutuhan ekonomi yang disebabkan karena kebutuhan rumah tangga yang besar dan mendesak sehingga membuat para ibu harus bekerja untuk dapat mencukupi kebutuhan hidup sehari-hari. Dalam hal ini, Hoffman (1984) juga menambahkan motif lain yang mendasari alasan kebutuhan ekonomi seperti penghasilan suami yang tidak mencukupi dan ibu yang menginginkan barang-barang berharga untuk diri serta anak-anaknya sehingga membutuhkan uang lebih untuk dapat membelinya. Keempat, ibu termotivasi untuk bekerja karena adanya aspek-aspek tertentu dari peran dalam keluarga yang memotivasi dirinya untuk mencari alternatif kegiatan selain berada di rumah, seperti kebosanan. Lainnya, yaitu untuk memenuhi kebutuhan psikologis seperti kontak sosial, kebutuhan untuk lebih dihargai karena status yang lebih tinggi, merealisasikan potensi, dan keinginan untuk berkontribusi bagi masyarakat (Hoffman, 1984).

Lebih jauh, apapun alasan yang melandasi keputusan wanita sebagai ibu untuk bekerja, beberapa hasil penelitian menunjukkan bahwa terdapat manfaat yang dapat diperoleh dari ibu bekerja. Penelitian mengenai kepuasan hidup dari wanita yang bekerja pernah dilakukan oleh Ferre (1976) menunjukkan bahwa ibu yang bekerja menunjukkan tingkat kepuasan hidup sedikit lebih tinggi dibandingkan dengan ibu yang tidak bekerja, meski ada beberapa faktor lain yang ikut menentukan, seperti peran suami yang mendukung.

Hanya, tidak dapat dipungkiri bahwa dibutuhkan usaha keras dari ibu yang bekerja agar dapat merasakan dampak positif dari bekerja. Secara khusus, ibu yang bekerja perlu bekerja keras untuk dapat mengintegrasikan kehidupan keluarga dan pekerjaan secara harmonis. Permasalahannya, hal tersebut sangatlah sulit karena orangtua yang bekerja akan memiliki kecenderungan berkomitmen tinggi terhadap pekerjaan atau keluarga (Greenberg \& Goldberg, 1989). Oleh karenanya, 
keseimbangan dalam komitmen terhadap pekerjaan dan keluarga merupakan hal yang sangat sulit dicapai oleh ibu bekerja walau memang bukan berarti tidak memungkinkan. Jadi, tidak mengherankan ketika konsekuensi negatif dari ibu bekerja merupakan hal yang paling sering ditonjolkan ketika membahas mengenai dampak dari ibu bekerja.

Dalam hal ini, berbicara mengenai dampak negatif dari ibu bekerja, salah satu dampak utama yang dapat dihasilkan adalah stress. Secara khusus, stress adalah kondisi yang muncul ketika individu mempersepsi bahwa mereka tidak dapat secara adekuat mengatasi tuntutan yang dibebankan pada mereka atau mengatasi ancaman yang mengancam kesejahteraan mereka (Lazarus, 1966). Higiens (1982) menyatakan bahwa faktor-faktor yang berperan dalam stress adalah kombinasi antara faktor eksternal (lingkungan) dan faktor internal (personal). Kedua faktor tersebut berperan dan berinteraksi dalam proses penilaian hingga terjadinya stress. Berikut adalah penjelasan lebih lanjut mengenai berbagai faktor eksternal dan faktor internal yang menyebabkan stress pada ibu bekerja.

Secara garis besar, faktor internal yang menyebabkan stress pada ibu bekerja serupa dengan faktor internal penyebab stress pada individu secara umum. Beberapa faktor internal yang dapat mempengaruhi stress pada ibu bekerja antara lain rasa percaya diri, motivasi, tipe kepribadian, keyakinan individu secara umum mengenai kehidupan sekitarnya dan kapasitas untuk mengontrolnya (Herlanti, Surmawan, dan Uripi 1995). Penjelasan lebih lanjut mengenai faktor-faktor tersebut dapat dilihat pada subbab faktor interal penyebab stress.

Menurut hasil penelitian yang dilakukan oleh Canadian Advisory Council mengenai Status of Women, stress ditemukan sebagai salah satu permasalahan kesehatan terbesar yang melanda ibu bekerja (Toronto Star, 1989). Hal ini diperkuat pula oleh McMartin (1999) yang melaporkan bahwa suatu studi internasional menemukan bahwa wanita mengalami tingkat stres yang lebih tinggi dalam hidupnya daripada pria, khususnya pada ibu yang memiliki anak dibawah usia 13 tahun yang bekerja penuh waktu. Lainnya, penemuan oleh Reid dan Hardy (1999) menemukan bahwa ibu yang bekerja dalam rentang jam kerja 20 hingga 40 jam menunjukkan simptom depresi yang paling tinggi. Adapun berkaitan dengan hal tersebut, beberapa penelitian mengungkapkan penyebabnya. Menurut penelitian yang dilakukan oleh 
Amato dan Booth (2003 dalam Kawamura, 2006), walau istri memiliki pekerjaan penuh waktu di luar rumah, istri tetap mengerjakan dua kali lebih banyak tugas-tugas rumah tangga daripada suami. Tidak hanya itu, selain dibebani oleh tugas-tugas rumah tangga, seorang ibu yang bekerja tetap memiliki tanggung jawab primer sebagai pengasuh utama anak. Jadi, dapat dikatakan bahwa seusai bekerja, ibu rumah tangga tidak dapat langsung beristirahat, melainkan harus tetap melakukan tugastugas lainnya tersebut. Secara khusus, fenomena ini dinamakan sebagai fenomena 'second shift' oleh Hoshschild (1989) yang berarti penambahan waktu 'kerja' yang lebih banyak bagi ibu bekerja daripada pria pekerja, yang telah mempunyai anak. Kemudian, sebagai seorang istri, ibu, dan juga seorang pekerja, ibu bekerja mengalami berbagai tuntutan dari peran-peran tersebut. Berbagai permintaan dan tekanan dari berbagai peran yang dialami oleh ibu bekerja pada akhirnya menyebabkan adanya ketegangan antar peran yang diemban oleh ibu bekerja yang selanjutnya menyebabkan kelelahan fisik dan emosi yang berimbas pada kondisi kesehatan dari ibu bekerja (Hochschild \& Machung, 1989). Dalam hal ini, akumulasi dari peran-peran yang diemban individu tersebut berhubungan secara positif dengan stres psikologis (Coser \& Rokoff, 1971).

Permasalahannya, beberapa penemuan yang telah diungkapkan sebelumnya pada dasarnya lebih banyak berasal dari hasil penelitian yang dilakukan di Amerika Serikat. Di Indonesia, walau penelitian mengenai stress pada ibu bekerja telah cukup banyak dilakukan, namun penelitian masih terbatas berupa penelitian kuantitatif yang hanya menyediakan informasi mengenai tingkat stres yang dialami atau kecenderungan teknik coping yang digunakan. Peneliti menemukan masih minimnya penelitian yang membahas mengenai gambaran stress pada ibu bekerja secara mendalam. Padahal, pembahasan mengenai gambaran stress pada ibu bekerja dalam hemat peneliti penting untuk dilakukan sebagai bentuk antisipasi terhadap dampak dari keputusan ibu untuk bekerja mempertimbangkan jumlah ibu bekerja di Indonesia, khususnya Medan, yang semakin meningkat. Oleh karena itu, penelitian ini dilakukan dengan maksud untuk mengetahui gambaran stress pada ibu bekerja yang tinggal di Medan. Secara khusus, gambaran stress yang dimaksud mencakup apa saja faktorfaktor penyebab stress, bagaimana dinamika interaksi dari faktor-faktor tersebut dalam menyebabkan stress, dampak stress bagi ibu bekerja, apa teknik coping yang 
digunakan, dan dampak dari teknik coping yang digunakan tersebut bagi ibu bekerja. Adapun partisipan dari penelitian ini adalah ibu bekerja yang berada dalam rentang usia 20-40 tahun yang memiliki anak dibawah 13 tahun dengan jumlah jam kerja 2040 jam per minggu.

Lebih jauh, penelitian ini akan dilakukan secara kualitatif dengan beberapa pertimbangan. Pertama, penelitian kualitatif digunakan untuk menghasilkan gambaran yang komprehensif dan lengkap tentang objek studi (Poerwandari, 2009). Hal ini sesuai dengan tujuan penelitian yang telah diungkapkan sebelumnya yaitu untuk memberikan informasi yang mendalam mengenai gambaran stress pada ibu bekerja yang tinggal di Medan. Kedua, yaitu adanya keterbatasan pada penelitian kuantitatif yang tidak mampu mengungkapkan fenomena khusus yang dialami subjek. Padahal, informasi spesifik tersebut dapat menjadi sumber pengetahuan yang kaya makna. Oleh karenanya, penelitian ini akan dilakukan secara kualitatif.

Pada akhirnya, dalam melaksanakan penelitian ini, peneliti memiliki dua tanggung jawab, yakni tanggung jawab ilmiah dan tanggung jawab kemanusiaan (Palys dalam Poerwandari, 2009). Tanggung jawab ilmiah merupakan tanggung jawab peneliti dalam mengembangkan pengetahuan dan pemahaman mengenai realitas sosial. Sementara, tanggung jawab kemanusiaan merupakan tanggung jawab peneliti terhadap subyek penelitian yang harus dijaga sebaik mungkin agar hak-hak atau kepentingan subyek maupun pihak-pihak yang terkait tidak dirugikan. Terkait dengan kedua tanggung jawab ini, maka peneliti akan berpegang pada etika-etika penelitian dalam melakukan penelitian. Peneliti tidak akan melakukan penipuan dengan cara mendistorsi data, seperti menciptakan data yang tidak sungguh-sungguh terjadi dikumpulkan di lapangan atau plagiarism. Peneliti juga akan menjaga kerahasiaan dan anonimitas subyek dengan tujuan menjaga hak-hak dan kepentingan subyek. Sebelum penelitian, subyek akan terlebih dahulu memperoleh informed consent, di mana subyek menyatakan persetujuannya untuk terlibat dalam penelitian setelah memperoleh informasi yang benar mengenai penelitian yang akan dilakukan ( Kvale, 1996 dan Neumann, 1997; Poerwandari, 2009). 


\section{METODE PENELITIAN}

\section{Partisipan}

Penelitian kualitatif tidak memberi batasan mengenai jumlah subjek penelitian Pada penelitian ini, peneliti hanya menggunakan satu subjek. Sampel dipilih dengan keriteria tertentu sesuai tujuan penelitian. Teknik ini digunakan agar sampel sungguhsungguh mewakili fenomena yang dipelajari (Poerwandari, 2009).

\section{Desain}

Penelitian ini menggunakan pendekatan kualitatif yang berusaha menjelaskan fenomena dari penghayatan subyektif subyek. Dalam hal ini, peneliti berpedoman pada metode penelitian kualitatif seperti yang dipaparkan oleh Poerwandari (2009) dalam buku 'Pendekatan Kualitatif untuk Penelitian Perilaku Manusia'.

\section{Teknik Pengumpulan Data}

Data untuk penelitian ini dikumpulkan dengan menggunakan wawancara dengan pedoman umum. Dalam hal ini, pedoman wawancara digunakan untuk mengingatkan peneliti mengenai aspek-aspek yang harus dibahas, sebagai daftar pengecek apakah aspek-aspek relevan tersebut telah dibahas atau ditanyakan. Adapun tujuan peneliti memilih metode ini adalah untuk mendapatkan data yang lebih kaya dan juga memungkinkan peneliti melaksanakan wawancara dengan lebih santai dan luwes. Urutan topik-topik yang harus ditanyakan dalam pedoman tidak harus dipatuhi, tetapi disesuaikan dengan alur wawancara agar wawancara dapat berjalan alami.

\section{Teknik Analisis}

Tahapan analisis data yang akan dilakukan dalam penelitian ini adalah sebagai berikut:

1. Membuat transkrip verbatim dari hasil wawancara dengan subjek. Pada tiap verbatim diberi inisial nama subjek dan waktu pengambilan data. 
2. Membaca hasil transkrip verbatim untuk mengetahui makna yang ada di dalam setiap kalimat dan berusaha untuk menemukan tema dan kategori yang berkaitan dengan masalah.

3. Membuat padatan fakta dan menentukan tema serta kategori yang muncul.

4. Membuat gambaran umum subjek.

5. Membuat riwayat mengenai pengalaman - pengalaman yang bersifat menekan dari ibu bekerja.

Melakukan analisis intrasubjek sesuai dengan kategori yang telah dibuat. 
Tabel 1. Gambaran Umum Subjek

\section{ANALISIS DAN HASIL}

\begin{tabular}{|c|c|c|c|c|c|c|}
\hline Subjek & Subjek 1 & Subjek 2 & Subjek 3 & Subjek 4 & Subjek 5 & Subjek 6 \\
\hline Usia Subjek & 30 tahun & 31 tahun & 27 tahun & 26 tahun & 26 tahun & 29 tahun \\
\hline $\begin{array}{l}\text { Kedudukan } \\
\text { Subjek dalam } \\
\text { Keluarga }\end{array}$ & $\begin{array}{l}\text { Anak kedua dari tiga } \\
\text { bersaudara }\end{array}$ & Anak tunggal & $\begin{array}{l}\text { Anak ke dua dari } \\
\text { dua bersaudara }\end{array}$ & $\begin{array}{l}\text { Anak ketiga } \\
\text { dari empat } \\
\text { bersaudara }\end{array}$ & $\begin{array}{l}\text { Anak pertama } \\
\text { dari dua } \\
\text { bersaudara }\end{array}$ & $\begin{array}{l}\text { anak ke. } 2 \text { dari } 2 \\
\text { bersaudara }\end{array}$ \\
\hline Agama & Kristen & Islam & Islam & Kristen & Islam & Islam \\
\hline $\begin{array}{l}\text { Tingkat } \\
\text { Pendidikan }\end{array}$ & SMEA Kesekretariatan & S1 Pariwisata & SMK Penjualan & S1 Akuntansi & $\begin{array}{l}\text { S1 Manajemen } \\
\text { Keuangan }\end{array}$ & $\begin{array}{l}\text { S1 Teknik } \\
\text { Lingkungan }\end{array}$ \\
\hline Pekerjaan & Staff divisi accounting & $\begin{array}{l}\text { Staff divisi Group } \\
\text { Desk Officer }\end{array}$ & $\begin{array}{l}\text { Staff divisi } \\
\text { marketing interior }\end{array}$ & $\begin{array}{l}\text { Staff divisi } \\
\text { accounting }\end{array}$ & $\begin{array}{l}\text { Funding } \\
\text { Officer }\end{array}$ & $\begin{array}{l}\text { Staff divisi } \\
\text { pengendalian } \\
\text { lingkungan hidup } \\
\text { (PNS) }\end{array}$ \\
\hline $\begin{array}{l}\text { Jumlah Jam } \\
\text { Kerja per } \\
\text { Minggu }\end{array}$ & 38 jam & 40 jam & 35 jam & 40 jam & 40 jam & 40 jam \\
\hline Suku bangsa & Tionghua & Minang \& Batak & Sunda & Batak & Jawa & Batak \\
\hline $\begin{array}{l}\text { Karakteristik } \\
\text { Perusahaan }\end{array}$ & $\begin{array}{l}\text { Perusahaan Keluarga, } \\
\text { bergerak di banyak bidang } \\
\text { mencakup kapal tongkang, }\end{array}$ & $\begin{array}{l}\text { Perusahaan asing } \\
\text { yang bergerak di } \\
\text { bidang jasa }\end{array}$ & $\begin{array}{l}\text { Perusahaan } \\
\text { penyedia jasa jual } \\
\text { beli dan }\end{array}$ & $\begin{array}{l}\text { Perusahaan } \\
\text { penyedia jasa } \\
\text { ekspor-impor }\end{array}$ & $\begin{array}{l}\text { Kantor cabang } \\
\text { sebuah Bank } \\
\text { Swasta }\end{array}$ & Kantor Walikota \\
\hline
\end{tabular}




\begin{tabular}{|c|c|c|c|c|c|c|}
\hline & kelapa sawit, batubara. & penerbangan & $\begin{array}{l}\text { penyewaan } \\
\text { apartemen }\end{array}$ & & & \\
\hline Lama kerja & 3 tahun & $\begin{array}{l}7 \text { tahun ( } 6 \text { tahun di } \\
\text { divisi yg lama, } 1 \\
\text { tahun di divisi group } \\
\text { desk officer) }\end{array}$ & 2 tahun & 4 tahun & 4 tahun & 3 tahun \\
\hline Lama menikah & 6 tahun & 7 tahun 11 bulan & 6 tahun & 2 tahun & 3 tahun & 3 tahun \\
\hline Jumlah Anak & 2 & 2 & 2 & 1 & 1 & 1 \\
\hline $\begin{array}{l}\text { Jenis Kelamin } \\
\text { Anak }\end{array}$ & Keduanya perempuan & $\begin{array}{l}\text { Laki-laki dan } \\
\text { perempuan }\end{array}$ & $\begin{array}{l}\text { Laki-laki dan } \\
\text { perempuan }\end{array}$ & Perempuan & Laki-laki & Laki-laki \\
\hline
\end{tabular}

Tabel 2. Gambaran Stress pada Ibu Bekerja

\begin{tabular}{|c|c|c|c|c|c|c|}
\hline $\begin{array}{c}\text { Subjek } \\
\text { Kategori }\end{array}$ & Subjek 1 & Subjek 2 & Subjek 3 & Subjek 4 & Subjek 5 & Subjek 6 \\
\hline $\begin{array}{l}\text { Faktor } \\
\text { penyebab } \\
\text { stress: faktor } \\
\text { internal }\end{array}$ & $\begin{array}{c}\text { Kepribadia: tidak } \\
\text { teridentifikasi } \\
\text { kepribadian A/B } \\
\text { namun } \\
\text { teridentifikasi } \\
\text { memiliki aspek } \\
\text { tidak sabaran } \rightarrow \\
\text { kekesalan dengan }\end{array}$ & $\begin{array}{c}\text { Tidak } \\
\text { teridentifikasi } \\
\text { adanya faktor } \\
\text { internal pada diri } \\
\text { subjek yang } \\
\text { menjadi } \\
\text { penyebab stres }\end{array}$ & $\begin{array}{c}\text { Tidak } \\
\text { teridentifikasi } \\
\text { adanya faktor } \\
\text { internal pada diri } \\
\text { subjek yang } \\
\text { menjadi penyebab } \\
\text { stres }\end{array}$ & $\begin{array}{l}\text { Tidak teridentifikasi } \\
\text { adanya faktor internal } \\
\text { pada diri subjek yang } \\
\text { menjadi penyebab stres }\end{array}$ & $\begin{array}{c}\text { Tidak teridentifikasi } \\
\text { adanya faktor internal } \\
\text { pada diri subjek yang } \\
\text { menjadi penyebab stress }\end{array}$ & $\begin{array}{l}\text { Tidak teridentifikasi } \\
\text { adanya faktor } \\
\text { internal pada diri } \\
\text { subjek yang menjadi } \\
\text { penyebab stress }\end{array}$ \\
\hline
\end{tabular}




\begin{tabular}{|c|c|c|c|c|c|c|}
\hline & bawahan & & & & & \\
\hline $\begin{array}{c}\text { Faktor } \\
\text { penyebab } \\
\text { stress: faktor } \\
\text { pekerjaan }\end{array}$ & $\begin{array}{l}\text { a. Tuntutan tugas: } \\
\text { routine job } \rightarrow \\
\text { membosankan, job } \\
\text { future ambiguity } \\
\rightarrow \quad \text { berlawanan } \\
\text { dengan } \\
\text { keinginannya } \\
\text { untuk memiliki } \\
\text { jenjang karir } \\
\text { b. Tuntutan peran: } \\
\text { interrole conflict } \\
\rightarrow \quad \text { berkonflik } \\
\text { dengan komitmen } \\
\text { yang tinggi pada } \\
\text { keluarga } \\
\text { c. Interpersonal } \\
\text { demands: social } \\
\text { density } \rightarrow \\
\text { berlawanan } \\
\text { dengan } \\
\text { kepribadiannya } \\
\text { yang suka bertemu } \\
\text { dengan banyak } \\
\text { orang dan } \\
\text { berbincang }\end{array}$ & $\begin{array}{l}\text { a. Physical } \\
\text { demands } \rightarrow \text { tata } \\
\text { letak ruangan yg } \\
\text { menyebabkan } \\
\text { banyak orang } \\
\text { salah masuk } \\
\text { ruangannya } \\
\text { b. Task } \\
\text { Demands: -- } \\
\text { routine job } \rightarrow \\
\text { membosankan, - } \\
\text { - work overload } \\
\rightarrow \text { lelah } \\
\text { c. Interpersonal } \\
\text { Demands: } \\
\text { Leadership style } \\
\rightarrow \text { atasan } \\
\text { menuntut tugas } \\
\text { untuk selesai } \\
\text { tapi tidak } \\
\text { memberikan } \\
\quad \text { solusi } \\
\text { d. Transitional } \\
\text { Factors } \rightarrow \\
\text { perubahan } \\
\text { sistem di kantor } \\
\text { yg menyebabkan } \\
\text { pekerjaan subjek } \\
\text { menjadi lebih }\end{array}$ & $\begin{array}{l}\text { a. Tuntutan } \\
\text { tugas : routine } \\
\text { job. Job } \\
\text { description } \\
\text { hanyalah } \\
\text { berjualan } \\
\text { sehingga merasa } \\
\text { bosan dengan } \\
\text { kegiatan } \\
\text { presentasi yang } \\
\text { itu-itu saja, } \\
\text { b. physical } \\
\text { demand: tidak } \\
\text { ada ventilasi } \\
\text { jendela di } \\
\text { ruangannya, } \\
\text { kantor terlalu } \\
\text { kecil sehingga } \\
\text { jika sedang ada } \\
\text { banyak } \\
\text { customer yang } \\
\text { datang, suasana } \\
\text { kantor dirasa } \\
\text { pengap dan } \\
\text { terlalu ramai }\end{array}$ & $\begin{array}{l}\text { a. } \\
\text { tugas : Occupational } \\
\text { Category } \rightarrow \text { terdapat } \\
\text { target yang harus } \\
\text { dicapai setiap bulan. } \\
\text { b. Hubungan dengan } \\
\text { rekan kerja : } \\
\text { - keterhambatan } \\
\text { dokumen yang berasal } \\
\text { dari rekan kerja } \\
\text { - rekan kerja yang } \\
\text { menurutnya cukup egois } \\
\text { dalam bekerja sehingga } \\
\text { terkadang sulit } \\
\text { membangun } \\
\text { komunikasi. }\end{array}$ & $\begin{array}{l}\text { a.physical demands } \rightarrow \\
\text { tempat duduk berada di } \\
\text { kawasan petinggi kantor } \\
\text { b. Tuntutan } \\
\text { tugas : Occupational } \\
\text { Category } \rightarrow \text { terdapat } \\
\text { target yang harus dicapai } \\
\text { setiap bulan. } \\
\text { Interactive } \\
\text { Organizational } \\
\text { Demands } \rightarrow \text { harus siap } \\
\text { sedia bertemu nasabah } \\
\text { pada waktu-waktu tak } \\
\text { terduga, bahkan di luar } \\
\text { jam kantor dan di hari } \\
\text { libur. } \\
\text { c. Tuntutan peran: } \\
\text { interrole conflict } \rightarrow \\
\text { terkadang diminta untuk } \\
\text { bekerja di luar jam } \\
\text { kantor atau di hari libur } \\
\text { yang merupakan hari } \\
\text { yang disediakan subjek } \\
\text { bagi keluarganya. } \\
\text { d. Hubungan dengan } \\
\text { rekan kerja } \rightarrow \text { terdapat } \\
\text { rekan kerja yang iri pada } \\
\text { subjek }\end{array}$ & 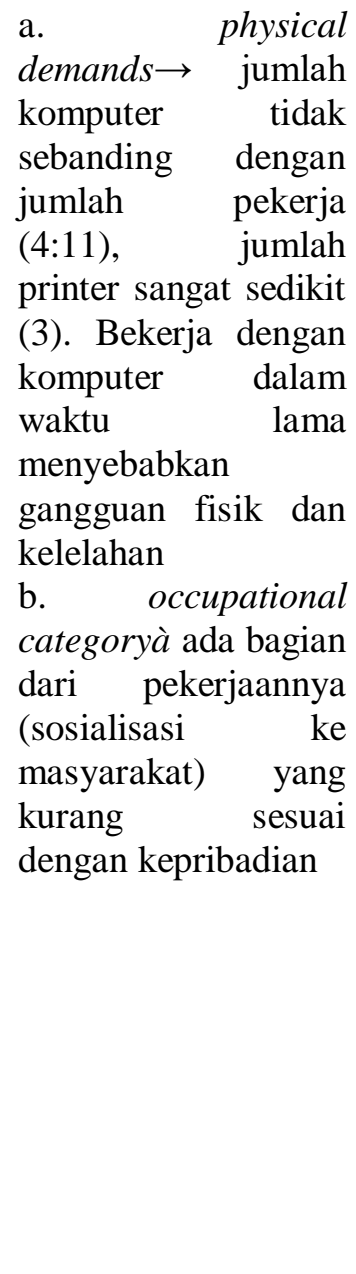 \\
\hline
\end{tabular}




\begin{tabular}{|c|c|c|c|c|c|c|}
\hline & & berat & & & & \\
\hline $\begin{array}{c}\text { Faktor } \\
\text { penyebab } \\
\text { stress: faktor } \\
\text { keluarga }\end{array}$ & $\begin{array}{l}\text { a. Anak bangun } \\
\text { tidur terlalu } \\
\text { awal } \rightarrow \\
\text { menyebabkan } \\
\text { kurang tidur dan } \\
\text { mengantuk } \\
\text { ketika bekerja }\end{array}$ & $\begin{array}{l}\text { a. Suami yg } \\
\text { kurang suka } \\
\text { jika subjek } \\
\text { melakukan } \\
\text { kerja lembur } \\
\text { b. Anak ada } \\
\text { masalah di } \\
\text { sekolahnya } \\
\text { (nilai yang } \\
\text { buruk) }\end{array}$ & $\begin{array}{l}\text { tidak } \\
\text { teridentifikasi } \\
\text { adanya stressor } \\
\text { yang berasal } \\
\text { dari keluarga }\end{array}$ & $\begin{array}{l}\text { tidak teridentifikasi } \\
\text { adanya stressor yang } \\
\text { berasal dari keluarga }\end{array}$ & $\begin{array}{l}\text { faktor keluarga tidak } \\
\text { menjadi penyebab stress } \\
\text { pada subjek }\end{array}$ & $\begin{array}{c}\text { Sifat suami yang } \\
\text { bertentangan dengan } \\
\text { dirinya }\end{array}$ \\
\hline $\begin{array}{c}\text { Faktor } \\
\text { penyebab } \\
\text { stress: } \\
\text { kategori } \\
\text { tambahan }\end{array}$ & $\begin{array}{l}\text { a. Pembantu } \\
\text { rumah tangga } \\
\text { pulang } \\
\text { kampung saat } \\
\text { lebaran terlalu } \\
\text { lama, ketika } \\
\text { sakit/tidak } \\
\text { datang } \rightarrow \\
\text { bertambah } \\
\text { beban pekerjaan } \\
\text { rumah tangga } \\
\text { padahal subjek } \\
\text { juga harus } \\
\text { mengurus anak } \\
\text { b. Sifat perusahaan } \\
\text { yang adalah } \\
\text { perusahaan } \\
\text { keluarga } \rightarrow\end{array}$ & & $\begin{array}{c}\text { a. Gosip yang } \\
\text { beberapa kali } \\
\text { beredar mengenai } \\
\text { dirinya yang tidak } \\
\text { benar, misalnya } \\
\text { digosipkan } \\
\text { berselingkuh } \\
\text { dengan pemilik unit } \\
\text { di apartemen atau } \\
\text { kliennya. } \\
\text { b. rekan kerja yang } \\
\text { iri jika ia berhasil } \\
\text { mendapat banyak } \\
\text { klien }\end{array}$ & & & $\begin{array}{l}\text { a.beban kerja yang } \\
\text { lebih berat karena } \\
\text { harus menanggung } \\
\text { tugas milik rekan } \\
\text { kerjanya yang malas } \\
\text { untuk menyelesaikan } \\
\text { tugas adminsitrasi }\end{array}$ \\
\hline
\end{tabular}




\begin{tabular}{|c|c|c|c|c|c|c|}
\hline & $\begin{array}{l}\text { subjek harus } \\
\text { menghadapi } \\
\text { sikap bos besar } \\
\text { dan istrinya } \\
\text { yang kerap } \\
\text { bertanya akan } \\
\text { urusan pribadi } \\
\text { anak-anaknya }\end{array}$ & & & & & \\
\hline $\begin{array}{l}\text { Faktor } \\
\text { penahan } \\
\text { stress: } \\
\text { psychological } \\
\text { resources }\end{array}$ & $\begin{array}{l}\text { a. Keyakinan } \\
\text { positif } \\
\text { b. Problem- } \\
\text { solving skills } \\
\text { c. Social support }\end{array}$ & $\begin{array}{l}\text { a. Keyakinan } \\
\text { positif } \\
\text { b. Problem } \\
\text { solving skills } \\
\text { c. Social skills } \\
\text { d. Social support }\end{array}$ & $\begin{array}{c}\text { a. Keyakinan } \\
\text { positif bahwa } \\
\text { segala sesuatu } \\
\text { harus dinikmati } \\
\text { b. Social support, } \\
\text { suami memberikan } \\
\text { dukungan } \\
\text { c. social skill }\end{array}$ & $\begin{array}{l}\text { a. Problem solving skills } \\
\text { b. Social support } \\
\rightarrow \text { suami selalu } \\
\text { mendukung pekerja } \\
\text { subjek, suami fleksibel } \\
\text { terhadap pembagian } \\
\text { tugas rumah tangga }\end{array}$ & $\begin{array}{l}\text { a. Keyakinan positif } \\
\text { b.Problem solving skills } \\
\text { c. Social skills } \\
\quad d \text {. Social support }\end{array}$ & $\begin{array}{l}\text { a. keyakinan positif } \\
\rightarrow \text { berpikiran positif } \\
\text { dalam menghadapi } \\
\text { masalah-masalah } \\
\text { yang dialaminya. } \\
\text { b.problem solving } \\
\text { c.social skills } \\
\text { d. social support dari } \\
\text { suami (fleksibel } \\
\text { dalam pembagian } \\
\text { tugas rumah tangga), } \\
\text { atasan (bimbingan } \\
\text { dalam pekerjaan) }\end{array}$ \\
\hline $\begin{array}{l}\text { Faktor } \\
\text { penahan }\end{array}$ & $\begin{array}{l}\text { a. Menggunakan } \\
\text { uang untuk }\end{array}$ & $\begin{array}{l}\text { a. Menggunakan } \\
\text { uang dan }\end{array}$ & $\begin{array}{l}\text { Menggunakan jasa } \\
\text { Tantenya yang }\end{array}$ & $\begin{array}{l}\text { a. Menggunakan } \\
\text { fasilitas kantor berupa }\end{array}$ & $\begin{array}{l}\text { Gaji mencukupi untuk } \\
\text { semua kebutuhan, }\end{array}$ & $\begin{array}{c}\text { a. menggunakan } \\
\text { pengasuh anak yang }\end{array}$ \\
\hline
\end{tabular}




\begin{tabular}{|c|c|c|c|c|c|c|}
\hline $\begin{array}{l}\text { stress: } \\
\text { material } \\
\text { resources }\end{array}$ & $\begin{array}{c}\text { menggunakan jasa } \\
\text { laundry } \rightarrow \\
\text { mengurangi beban } \\
\text { kerja rumah } \\
\text { tangga } \\
\text { b. Menggunakan } \\
\text { pembantu rumah } \\
\text { tangga pulang } \\
\text { pergi }\end{array}$ & $\begin{array}{l}\text { fasilitas yg } \\
\text { diberikan dari } \\
\text { kantor untuk } \\
\text { jalan-jalan } \\
\text { b. Menggunakan } \\
\text { jasa pembantu } \\
\text { untuk mengurus } \\
\text { kebutuhan } \\
\text { rumah tangga }\end{array}$ & $\begin{array}{c}\text { tinggal bersama } \\
\text { keluarga intinya } \\
\text { untuk membantu } \\
\text { pekerjaan rumah } \\
\text { tangga dan } \\
\text { menjagai anak } \\
\text { keduanya } \\
\text { (menggaji Tantenya } \\
\text { juga) }\end{array}$ & $\begin{array}{l}\text { komputer dan internet } \\
\text { untuk mengatasi } \\
\text { masalah keterlambatan } \\
\text { data dari rekan kerja } \\
\text { b. Menggunakan jasa } \\
\text { pembantu untuk } \\
\text { mengurus kebutuhan } \\
\text { rumah tangga }\end{array}$ & $\begin{array}{l}\text { terdapat bonus gaji } \\
\text { setiap tahun, kantor } \\
\text { menyediakan fasilitas } \\
\text { kesehatan dan asuransi. }\end{array}$ & $\begin{array}{l}\text { sekaligus berrtugas } \\
\text { membantu mengurus } \\
\text { beberapa pekerjaan } \\
\text { rumah tangga } \\
\text { b. saudara yang } \\
\text { memasakan makanan } \\
\text { di rumah }\end{array}$ \\
\hline
\end{tabular}




\begin{tabular}{|c|c|c|c|c|c|c|}
\hline $\begin{array}{c}\text { Faktor } \\
\text { penahan } \\
\text { stress: faktor } \\
\text { eksternal } \\
\text { (pekerjaan) }\end{array}$ & $\begin{array}{l}\text { a. Beban kerja di } \\
\text { kantor tidak } \\
\text { terlalu banyak } \\
\text { b. Pekerjaan } \\
\text { subjek tidak } \\
\text { terlalu rumit } \\
\text { c. Sikap atasan } \\
\text { yang fleksibel } \\
\text { memberikan ijin } \\
\text { masuk siang, } \\
\text { jarang ngomel, } \\
\text { orang yang } \\
\text { simpel. } \\
\text { d. Jarak rumah dan } \\
\text { kantor yang } \\
\text { dekat } \\
\text { e. Terkadang } \\
\text { diberikan uang } \\
\text { tip dari supplier }\end{array}$ & $\begin{array}{l}\text { a. Pekerjaan yg } \\
\text { tidak berat dan } \\
\text { tidak } \\
\text { membutuhkan } \\
\text { banyak mobilitas } \\
\text { b. Adanya } \\
\text { dispensasi dari } \\
\text { kantor untuk } \\
\text { mengambil cuti } \\
\text { atau izin jika } \\
\text { sakit } \\
\text { c. Ruangan } \\
\text { kantor yang } \\
\text { berisikan } 2 \\
\text { orang saja } \\
\text { sehingga } \\
\text { membuat subjek } \\
\text { merasa nyaman }\end{array}$ & $\begin{array}{l}\text { a. Dispensasi dari } \\
\text { kantor, mudah } \\
\text { mengambil waktu } \\
\text { libur atau izin } \\
\text { b. pekerjaan subjek } \\
\text { tidak terlalu rumit } \\
\text { c. atasan bersikap } \\
\text { fleksibel. walaupun } \\
\text { ada target yang } \\
\text { tidak tercapai, tidak } \\
\text { jadi masalah } \\
\text { c. jarak kantor dan } \\
\text { rumah tidak jauh } \\
\text { d. jam lembur tidak } \\
\text { sering } \\
\text { e. beban kerja tidak } \\
\text { terlalu banyak }\end{array}$ & $\begin{array}{l}\text { a. Beban kerja tidak } \\
\text { terlalu banyak dan } \\
\text { mobilitas rendah } \\
\text { b. Tidak pernah lembur } \\
\text { c. Tugas kantor bersifat } \\
\text { individual sehingga } \\
\text { deadline tugas dapat } \\
\text { diatur sendiri }\end{array}$ & $\begin{array}{l}\text { a. Atasan dan rekan kerja } \\
\text { subjek bersikap } \\
\text { fleksibel, } \\
\text { memperhatikan dan } \\
\text { menghargai subjek } \\
\text { b.perkembangan karir } \\
\text { yang baik } \\
\text { c. Pekerjaan yang } \\
\text { dilakukan di dalam } \\
\text { maupun di luar kantor } \\
\text { meminimalisir } \\
\text { kejenuhan pada diri } \\
\text { subjek ketika bekerja }\end{array}$ & $\begin{array}{c}\text { a. jenis pekerjaan } \\
\text { yang sesuai dengan } \\
\text { minat diri } \\
\text { b. mudah pengurusan } \\
\text { izin } \\
\text { tidak masuk kantor } \\
\text { c. jam kerja lebih } \\
\text { singkat dibanding } \\
\text { pekerjaan dulu }\end{array}$ \\
\hline
\end{tabular}




\begin{tabular}{|c|c|c|c|c|c|c|}
\hline & & $\begin{array}{l}\text { mengenai tugas } \\
\text { rumah tangga }\end{array}$ & $\begin{array}{l}\text { kredit kendaraan } \\
\text { dengan suami } \\
\text { sehingga keuangan } \\
\text { lebih terorganisir }\end{array}$ & & & \\
\hline $\begin{array}{c}\text { Faktor } \\
\text { penahan } \\
\text { stress: faktor } \\
\text { eksternal } \\
\text { (kategori } \\
\text { pengalaman) }\end{array}$ & $\begin{array}{l}\text { a. Pengalaman } \\
\text { terbiasa } \\
\text { mengerjakan tugas } \\
\text { rumah tangga } \\
\rightarrow \text { merasa } \\
\text { pekerjaan rumah } \\
\text { tangga tidak berat }\end{array}$ & $\begin{array}{l}\text { a. Pengalaman } \\
\text { subjek yg pernah } \\
\text { bekerja di divisi } \\
\text { yg lebih berat } \rightarrow \\
\text { merasa } \\
\text { pekerjaannya } \\
\text { saat ini tidak } \\
\text { berat }\end{array}$ & $\begin{array}{l}\text { a. Pengalaman } \\
\text { pernah mudah } \\
\text { merasa tertekan dan } \\
\text { stress, dirasa sangat } \\
\text { mengganggu, } \\
\text { kemudian belajar } \\
\text { mengubah pola } \\
\text { pikir agar waktunya } \\
\text { tidak terbuang sia- } \\
\text { sia }\end{array}$ & $\begin{array}{l}\text { a. Pengalaman subyek } \\
\text { yang sudah pernah } \\
\text { menghadapi beban kerja } \\
\text { yang lebih berat di } \\
\text { perusahaan sebelumnya }\end{array}$ & $\begin{array}{c}\text { a. sudah bekerja sejak } \\
\text { kantor tersebut } \\
\text { didirikan--> } \\
\text { memiliki pengalaman } \\
\text { menempati posisi yang } \\
\text { berbeda-beda di kantor } \\
\text { dan mengetahui cara } \\
\text { menyelesaikan masalah } \\
\text { di kantor }\end{array}$ & \\
\hline $\begin{array}{l}\text { Strategi } \\
\text { Coping } \\
\text { terhadap } \\
\text { Stressor }\end{array}$ & $\begin{array}{l}\text { a. Emotion- } \\
\text { focused coping } \rightarrow \\
\text { mengubah mood } \\
\text { yang buruk } \\
\text { dengan cara } \\
\text { bercerita pada } \\
\text { teman } \\
\text { b. Problem- } \\
\text { focused coping } \rightarrow \\
\text { melakukan } \\
\text { reappraisal } \\
\text { terhadap situasi, } \\
\text { meminta bantuan } \\
\text { keluarga dan } \\
\text { suami, }\end{array}$ & $\begin{array}{l}\text { a. Emotional } \\
\text { focused coping } \\
\rightarrow \text { mengubah } \\
\text { mood jd lebih } \\
\text { baik dengan cara } \\
\text { bercerita pada } \\
\text { teman, } \\
\text { mengobrol } \\
\text { dengan orang } \\
\text { dari travel agent, } \\
\text { mendengarkan } \\
\text { musik saat di } \\
\text { ruangan kantor } \\
\text { b. Problem } \\
\text { focused coping }\end{array}$ & $\begin{array}{l}\text { a. Emotional- } \\
\text { focused coping } \rightarrow \\
\text { agar mood menjadi } \\
\text { lebih baik dan bisa } \\
\text { berpikir untuk } \\
\text { memecahkan } \\
\text { masalah. Kegiatan } \\
\text { yang dilakukan } \\
\text { antara lain } \\
\text { berbelanja, } \\
\text { karaoke, jalan- } \\
\text { jalan., saat } \\
\text { menghadapi } \\
\text { masalah } \\
\text { digosipkan, subjek }\end{array}$ & $\begin{array}{l}\text { a.Emotional-focused } \\
\text { coping } \rightarrow \text { berbagi cerita } \\
\text { dengan suami untuk } \\
\text { menenangkan diri ketika } \\
\text { ada masalah yang } \\
\text { dihadapi } \\
\text { b.problem-focused } \\
\text { coping } \rightarrow \text { mencari } \\
\text { solusi langsung atas } \\
\text { keterlambatan data yang } \\
\text { ia butuhkan }\end{array}$ & $\begin{array}{c}\text { a. emotion-focused } \rightarrow \\
\text { bercerita pada suami dan } \\
\text { rekan kerja mengenai } \\
\text { nasabah yang kurang } \\
\text { menyenangkan } \\
\text { b. problem-focused } \rightarrow \\
\text { melakukan reappraissal } \\
\text { terhadap } \\
\text { situasi ,mengatur waktu } \\
\text { pertemuan dengan } \\
\text { nasabah,menjauhi teman } \\
\text { yang menunjukkan rasa } \\
\text { sirik, mempercepat } \\
\text { penyelesaian tugas } \\
\text { kantor. }\end{array}$ & $\begin{array}{l}\text { a. emotion focused-- } \\
\text { >pergi karaoke untuk } \\
\text { mengatasi kejenuhan } \\
\text { setelah bekerja } \\
\text { b. problem focused-- } \\
\text { > membawa laptop } \\
\text { sendiri untuk } \\
\text { mengatasi } \\
\text { terbatasnya jmlh } \\
\text { komputer, } \\
\text { melakuakan } \\
\text { reappraisal:bagian } \\
\text { pekerjaan yg tidak } \\
\text { disukai sudah } \\
\text { merupakan tuntutan }\end{array}$ \\
\hline
\end{tabular}




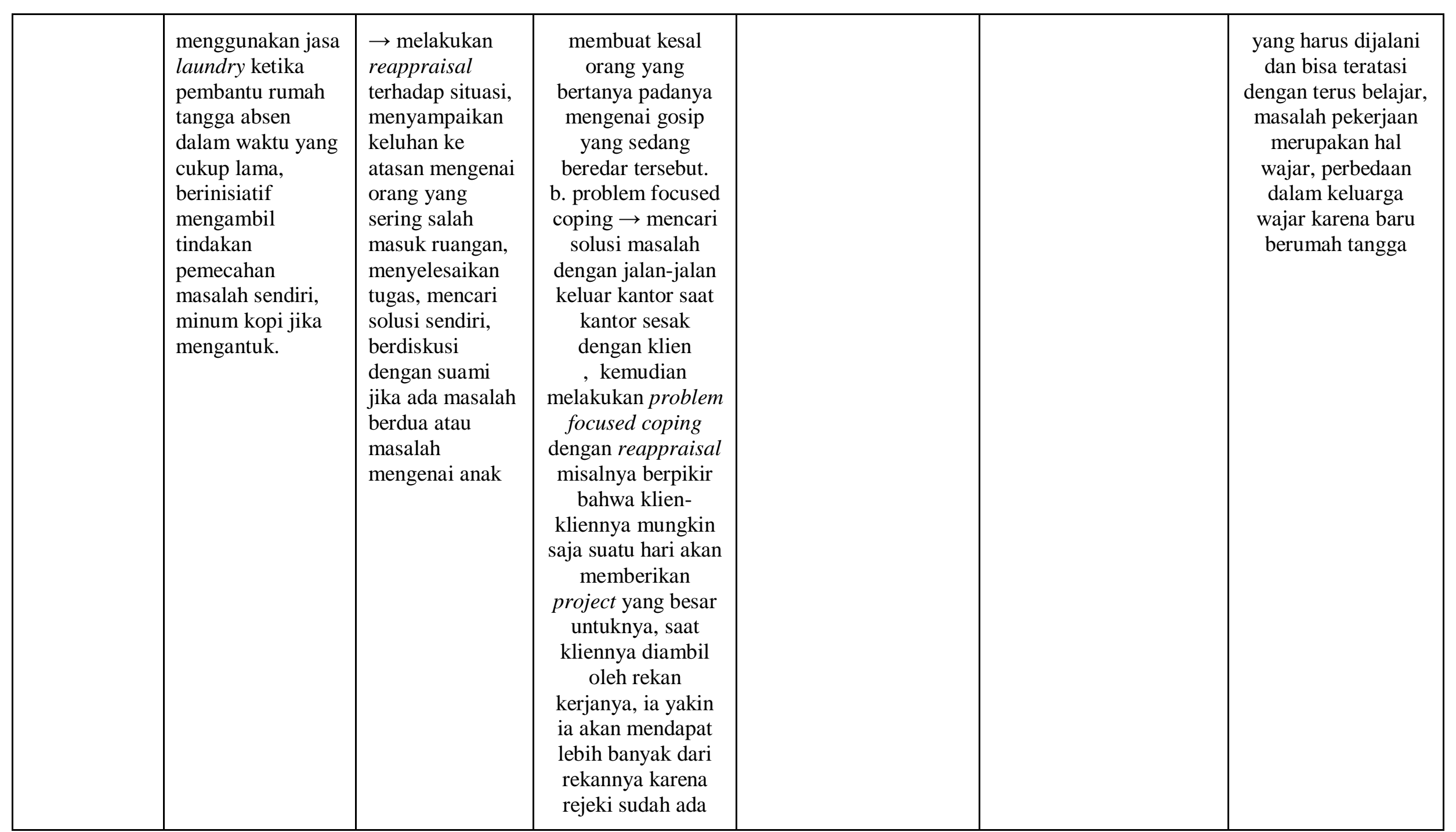




\begin{tabular}{|c|c|c|c|c|c|c|}
\hline & & & $\begin{array}{l}\text { yang mengatur, saat } \\
\text { menghadapi gosip } \\
\text { ia hanya berpikir } \\
\text { temannya iri } \\
\text { padanya dan yakin } \\
\text { tidak ada bukti dan } \\
\text { tidak melakukan } \\
\text { kesalahan sehingga } \\
\text { tidak perlu } \\
\text { khawatir berlebihan }\end{array}$ & & & \\
\hline $\begin{array}{l}\text { Dampak dari } \\
\text { Strategi } \\
\text { Coping }\end{array}$ & $\begin{array}{l}\text { Strategi coping } \\
\text { yang digunakan } \\
\text { sejauh ini berhasil } \\
\text { / efektif mengatasi } \\
\text { stressor yang } \\
\text { muncul. }\end{array}$ & $\begin{array}{l}\text { Strategi coping } \\
\text { yang digunakan } \\
\text { berhasil untuk } \\
\text { mengatasi } \\
\text { stressor. }\end{array}$ & $\begin{array}{l}\text { Strategi coping } \\
\text { efektif mengatasi } \\
\text { stressor yang } \\
\text { muncul, }\end{array}$ & $\begin{array}{c}\text { Strategi coping yang } \\
\text { digunakan efektif dalam } \\
\text { mengatasi } \\
\text { stressor yang muncul. }\end{array}$ & $\begin{array}{l}\text { Strategi coping yang } \\
\text { digunakan secara efektif } \\
\text { mengatasi stressor yang } \\
\text { muncul. }\end{array}$ & $\begin{array}{l}\text { Strategi coping yang } \\
\text { digunakan secara } \\
\text { efektif mengatasi } \\
\text { stressor yang } \\
\text { muncul. }\end{array}$ \\
\hline $\begin{array}{c}\text { Dampak dari } \\
\text { Stress }\end{array}$ & $\begin{array}{l}\text { Tidak } \\
\text { mengidentifikasi } \\
\text { adanya dampak } \\
\text { negatif dari stress } \\
\text { pada individu } \rightarrow \\
\text { subjek didukung } \\
\text { oleh sejumlah } \\
\text { banyak faktor } \\
\text { penahan stress } \\
\text { baik dari internal } \\
\text { maupun eksternal }\end{array}$ & $\begin{array}{l}\text { Tidak } \\
\text { teridentifikasi } \\
\text { adanya dampak } \\
\text { negatif dari } \\
\text { stress } \rightarrow \\
\text { didukung oleh } \\
\text { sejumlah banyak } \\
\text { faktor penahan } \\
\text { stress baik dari } \\
\text { internal maupun } \\
\text { eksternal }\end{array}$ & $\begin{array}{c}\text { Tidak } \\
\text { teridentifikasi } \\
\text { adanya dampak } \\
\text { negatif stress pada } \\
\text { individu stress } \\
\text { yang dialami } \\
\text { individu } \\
\rightarrow \text { adanya dukungan } \\
\text { dari beberapa } \\
\text { faktor penahan } \\
\text { stress, baik internal } \\
\text { maupun eksternal }\end{array}$ & $\begin{array}{c}\text { Tidak teridentifikasi } \\
\text { adanya dampak negatif } \\
\text { dari }\end{array}$ & $\begin{array}{c}\text { Tidak teridentifikasi } \\
\text { adanya dampak negatif } \\
\text { dari stress pada individu } \\
\rightarrow \text { berbagai faktor } \\
\text { penahan stress baik } \\
\text { internal maupun } \\
\text { eksternal mampu } \\
\text { menghindari subjek dari } \\
\text { stress }\end{array}$ & $\begin{array}{c}\text { Tidak teridentifikasi } \\
\text { adanya dampak } \\
\text { negatif dari stress } \\
\text { pada individu } \rightarrow \\
\text { berbagai faktor } \\
\text { penahan stress baik } \\
\text { internal maupun } \\
\text { eksternal mampu } \\
\text { menghindari subjek } \\
\text { dari stress }\end{array}$ \\
\hline
\end{tabular}




\section{SIMPULAN DAN SARAN}

\section{Simpulan}

1. Faktor yang menyebabkan stress pada ibu bekerja yang tinggal di Medan dominan disebabkan oleh faktor pekerjaan. Selain faktor pekerjaan, faktor keluarga juga menjadi salah satu penyebab stres pada ibu bekerja, seperti sifat suami dan prestasi anak. Faktor tambahan seperti asisten rumah tangga juga menjadi salah satu faktor penyebab namun teridentifikasi dalam jumlah yang kecil.

2. Stres pada ibu bekerja tidak menimbulkan dampak yang signifikan dimana ibu bekerja memiliki faktor penahan stres berupa internal dan eksternal. Faktor penahan stres bersifat internal kebanyakan berupa kesehatan yang terjaga serta memiliki energi yang tinggi, keyakinan positif, kemampuan menyelesaikan masalah dan dukungan sosial yang cukup memadai. Tingkat kepercayaan, self esteem serta komitmen yang tinggi juga menjadi faktor internal yang meminimalisir dampak stres pada ibu bekerja. Sementara, faktor eksternal berupa pengalaman menjadi faktor penahan stres yang terlihat baik pada ibu bekerja dimana pekerjaan kantor dan rumah terasa semakin mudah karena sudah terbiasa mengerjakannya. Selain itu, material resources juga menjadi faktor penahan stres pada hampir semua ibu bekerja, khususnya dengan suami bekerja juga dimana mereka dapat menggunakan jasa tambahan seperti laundry atau penggunaan jasa asisten rumah tangga untuk membantu tugas ibu bekerja.

3. Rata-rata ibu bekerja dapat menggunakan strategi coping stres baik emotionfocused maupun problem-focused.sehingga dapat mengatasi masalah yang mungkin muncul dalam lingkungan rumah tangga maupun pekerjaan.

\section{Saran}

\section{Saran Metodologis}

1. Peneliti menyarankan untuk penelitioan selanjutnya, karakteristik jenis pekerjaan subyek lebih divariasikan sehingga akan diperoleh gambaran mengenai ibu bekerja yang lebih 
bervariasi dan mendalam. Selain itu, variasi juga dapat dilakukan terkait jumlah dan usia anak dari ibu bekerja.

2. Dalam penelitian ini, ibu bekerja yang menjadi subyek penelitian seluruhnya merupakan individu yang memiliki suami sehingga tidak ada variasi dalam kondisi keluarga. Oleh karena itu, untuk penelitian selanjutnya dapat juga dilakukan pada ibu bekerja single mother agar diperoleh gambaran yang lebih mendalam mengenai peran faktor keluarga terhadap stres yang dialami ibu bekerja.

\section{Saran Praktis}

Berdasarkan hasil penelitian, ditemukan bahwa faktor-faktor pelindung dan strategi coping yang digunakan berpengaruh pada tingkat stres yang dirasakan pada ibu bekerja. Oleh karena itu,bagi pembaca yang akan memutuskan untuk bekerja sebaiknya mempertimbangkan faktor-faktor tersebut sehingga mereka dapat mengantisipasi kemungkinan stres yang akan dirasakan dan cara-cara untuk mengatasinya.

\section{REFERENSI}

Coser, R.L. \& Rokoff, G. (1971). Women in occupational world: social disruption and conflict. Social Problems, 535-554.

Dubeck, P. \& Borman, K. . (1996). The handbook of women and work. New York: Garland Press.

Ferree, M. M. (1976). Working-class jobs: Paid work and housework as sources of satisfaction. Social Problems, 23(4).

Herlanti, Y., Surmawan, U., dan Uripi, V. (n.d.). Faktor-faktor yang mempengaruhi gejala fisik dan gejala jiwa stress pada ibu bekerja dan tidak bekerja. Media Gizi Dan Keluarga, 1995, 18-26.

Hoffman, L. W. (1984). Maternal employment and the young child. In M. Perlmutter (Ed.), Parent- child interaction and parent- child relations in child development. In Hillsdale. NJ: Erlbaum.

Lazarus, R. S. (1966). Psychological Stress and the Coping Process. New York: 


\section{McGrawHil.}

McMartin, P. (1999). Women suffer more stress than men, study claims: Working mothers with young children reported the highest stress levels.

Poerwandari, E. K. (2009). Pendekatan Kualitatif untuk Penelitian Perilaku Indonesia. Depok. LPSP3 UI.

Reid, J.,\& Hardy, M. (1999). Multiple roles and well-being among midlife women: testing role strain and role enchancement theories. Journal of Gerontology.

Siregar, S. D. (2011). Peran ibu bekerja dan tidak bekerja terhadap pendidikan anak di rumah pada masyarakat mandailing di kelurahan bonan dolok kecamatan padang sidempuan utara. Retrieved from http://repository.usu.ac.id/handle/123456789/28173 